\title{
Utility of Washington Early Recognition Center Self-Report Screening Questionnaires in the Assessment of Patients with Schizophrenia and Bipolar Disorder
}

OPEN ACCESS

Edited by:

Alexandre Andrade Loch, University of São Paulo, Brazil

Reviewed by: Victor Lasebikan, University of Ibadan, Nigeria Jude Uzoma Ohaeri, University of Nigeria, Nigeria

${ }^{*}$ Correspondence: Christina J. Hsieh hsiehcj@slu.edu

Specialty section: This article was submitted to Public Mental Health, a section of the journal Frontiers in Psychiatry

Received: 05 July 2016 Accepted: 15 August 2016 Published: 26 August 2016

Citation: Hsieh CJ, Godwin D and Mamah D (2016) Utility of Washington Early Recognition Center Self-Report

Screening Questionnaires in the Assessment of Patients with Schizophrenia and Bipolar Disorder.

Front. Psychiatry 7:149.

doi: 10.3389/fpsyt.2016.00149

\section{Christina J. Hsieh ${ }^{1,2 *}$, Douglass Godwin ${ }^{2}$ and Daniel Mamah ${ }^{2}$}

${ }^{1}$ Saint Louis University School of Medicine, St. Louis, MO, USA, ${ }^{2}$ Department of Psychiatry, Washington University Medical School, St. Louis, MO, USA

Early identification and treatment are associated with improved outcomes in bipolar disorder (BPD) and schizophrenia (SCZ). Screening for the presence of these disorders usually involves time-intensive interviews that may not be practical in settings where mental health providers are limited. Thus, individuals at earlier stages of illness are often not identified. The Washington Early Recognition Center Affectivity and Psychosis (WERCAP) screen is a self-report questionnaire originally developed to identify clinical risk for developing bipolar or psychotic disorders. The goal of the current study was to investigate the utility of the WERCAP Screen and two complementary questionnaires, the WERC Stress Screen and the WERC Substance Screen, in identifying individuals with established SCZ or BPD. Participants consisted of 35 BPD and 34 SCZ patients, as well as 32 controls (CON), aged 18-30 years. Univariate analyses were used to test for score differences between groups. Logistic regression and receiver operating characteristic $(\mathrm{ROC})$ curves were used to identify diagnostic predictors. Significant group differences were found for the psychosis section of the WERCAP (pWERCAP; $p<0.001$ ), affective section of the WERCAP (aWERCAP; $p=0.001$ ), and stress severity $(p=0.027$ ). No significant group differences were found in the rates of substance use as measured by the WERC Substance Screen $(p=0.267)$. Only the aWERCAP and pWERCAP scores were useful predictors of diagnostic category. ROC curve analysis showed the optimal cut point on the aWERCAP to identify BPD among our participant groups was a score of $>20$ [area under the curve (AUC): 0.87; sensitivity: 0.91; specificity: 0.71], while that for the pWERCAP to identify SCZ was a score of >13 (AUC: 0.89; sensitivity: 0.88; specificity: 0.82). These results indicate that the WERCAP Screen may be useful in screening individuals for BPD and SCZ and that identifying stress and substance-use severity can be rapidly done using self-report questionnaires. Larger studies in undiagnosed individuals will be needed to test the WERCAP Screen's ability to identify mania or psychosis in the community.

Keywords: bipolar disorder, schizophrenia, WERCAP, psychosis, stress, questionnaire 


\section{INTRODUCTION}

Schizophrenia (SCZ) and bipolar disorder (BPD) are complex mental illnesses with onset in adolescence and are among the leading causes of disability worldwide (1). Early identification and initiation of antipsychotic therapy are associated with improved prognoses in SCZ, whereas longer durations of untreated illness are associated with worse outcomes $(2,3)$. This holds true across different nations and cultures $(4,5)$. Similarly, in BPD, delayed diagnosis and treatment are associated with more hospitalizations, increased suicidality (6), and impaired social function (7). Patients with recurrent depressive episodes in BPD may be misdiagnosed with unipolar depression, leading to a longer duration of untreated illness and worse outcomes (8-10). Misdiagnosis and inappropriate treatment with antidepressants can increase mania and exacerbation of the episode (11). In some practices, it takes an average of about 10 years between the onset of BPD and initiation of treatment with mood stabilizers (12). The challenges involved in early recognition and treatment of SCZ and BPD support the need for a reliable screening instrument.

Bipolar disorder and SCZ are typically diagnosed by a clinician or by structured clinical interviews, which are time consuming and, therefore, not practical for screening purposes. Commonly used screening questionnaires in BPD, such as the Altman SelfRating Mania Scale (13), Young Mania Rating Scale (14), or the Bipolar Spectrum Diagnostic Scale (BSDS) (15), either probe for severity of current manic-like symptoms or generate unacceptably high rates of false positives and low sensitivity (16). For example, the Mood Disorders Questionnaire, the most extensively studied of instruments for detecting $\mathrm{BPD}$, was found to have a positive predictive value (PPV) of $22.1 \%$ (17). Likewise, the BSDS has a PPV of only $16 \%$ (18). Thus, the need for a rapid and reliable means to screen for BPD remains unmet. Similarly, the community assessment of psychic experiences (CAPE)-42, a screening instrument for detecting psychosis, has a PPV of only $23.5 \%$ (19). Other rating instruments commonly used in assessing SCZ or other psychotic disorders, such as the Scale for the Assessment of Positive Symptoms (20) or the Positive and Negative Syndrome Scale (21), probe for current psychotic symptoms and are not designed to assist in diagnosis.

The Washington Early Recognition Center Affectivity and Psychosis (WERCAP) screen was developed to accurately and efficiently identify individuals at risk of bipolar and psychotic disorders. The WERCAP Screen is a quantitative measure of affective and psychotic symptoms that elicits information about symptom frequency and the degree of resulting dysfunction ("functionality"). The WERCAP Screen has been validated in a non-clinical youth population in the US, provides results comparable to the structured interview for prodromal syndromes (SIPS) in a much shorter period of time, and is designed to be cross-culturally applicable (22). The WERCAP Screen has two sections, the aWERCAP and pWERCAP, which measure the risk of developing BPD ("affectivity") and psychosis, respectively. Unlike other screening instruments, the WERCAP Screen was designed to assess chronic or lifetime affective or psychotic symptoms (although a time interval can be specified for more acute symptoms). Thus, it could potentially be used to identify individuals with established bipolar or psychotic disorder diagnoses and also inform on illness severity.

Stress (23) and substance use (24) are both associated with risk of psychosis and decompensation in those with psychotic or BPDs; thus, reliably assessing their severities could provide valuable information for clinicians. A number of substances have been found to be associated with risk of psychosis and BPD, most commonly tobacco $(25,26)$ and cannabis $(27)$. There is now strong evidence suggesting that cannabis use can trigger the onset of psychosis (28-30). Progression to greater cannabis usage frequency is associated with greater risk of psychosis (31). Higher rates of cannabis use have been consistently linked with earlier age of onset in psychosis (30,32-35) with some studies reporting a similar association in BPD (36-38).

Substance use has also been reported to exacerbate symptoms in patients that have already been diagnosed with SCZ and BPD. SCZ patients with a history of cannabis use tend to have longer hospital stays and more frequent readmissions compared to cannabis non-users (39). Cannabis use is also linked with an increase in psychotic (40-43) and manic symptoms (44). Cannabis use is associated with worse treatment outcomes and functioning in patients with psychosis $(45-47)$ and BPD $(48,49)$. Some studies have also found tobacco use to be associated with greater illness severity (50). Tobacco smoking is highly prevalent among SCZ and bipolar patients (51) and has been associated with worse outcomes and lower remission rates in $\operatorname{BPD}(49,52)$. In addition, there have been case reports of psychiatric relapse following excessive caffeine consumption in patients suffering from SCZ (53) and BPD (54).

Psychosocial stress is another risk factor shared between SCZ and BPD, along with other psychiatric disorders $(55,56)$. There is extensive evidence linking early childhood trauma with increased risk of psychosis (57-59) and BPD (60). It has been hypothesized that childhood adversity results in increased vulnerability to stress and psychiatric disorder (61). SCZ, BPD, and depression patients all tend to report increased sensitivity to stress (62). Moreover, greater exposure to childhood adversity has been correlated with higher levels of perceived stress and increased psychopathology (63). Stressors later in life have also been found to increase the risk of psychotic (64) and manic (65-67) episodes. More recent studies have reported everyday stressors in adult life to be correlated with an increase in psychotic (68) and manic (69) symptoms. Thus, assessing stress severity could conceivably improve the identification of individuals at risk for psychosis and BPD.

We have previously developed tools to capture psychosocial stress load and substance-use habits. The WERC Stress Screen (hereafter referred to as "Stress Screen") is a self-report questionnaire that assesses the overall stress burden currently experienced by the individual, and also quantifies the individual contributions of common psychosocial stressors to the total stress burden (22). The WERC Substance Screen (hereafter referred to as "Substance Screen") allows respondents to selfreport on the usage frequencies of multiple substances that may influence brain function.

The current study explores the utility of our quantitative screening instruments in a sample of patients with SCZ and 
BPD. Our objective was to determine whether the WERCAP Screen, Stress Screen, or Substance Screen could predict diagnosis in a clinical population and the optimal cutoff thresholds on these instruments. We hypothesized that the measures of psychosis and affectivity would be the most useful predictors of diagnosis.

\section{MATERIALS AND METHODS}

The Institutional Review Board of Washington University Medical School in St. Louis approved all procedures and study materials. All participants in the study provided informed consent.

\section{Participants}

One hundred two individuals ages 18-30 years participated in the study, which consisted of three groups: BPD (BPD, $n=35)$, SCZ (SCZ, $n=34$ ), and healthy controls (CON, $n=32$ ). Participants were recruited using a combination of flyers posted in public locations, recruitment information posted to university websites, as well as clinic referrals. Consequently, our sample size was limited by clinical availability of individuals with SCZ and BPD who met inclusion criteria. Diagnosis was determined based on the agreement of assessments by a research psychiatrist and a trained research assistant using the structured clinical interview for DSM-IV axis I disorders (SCID-I) and the structured clinical interview for DSM-IV axis II disorders (SCID-II), with precedence given to the psychiatrist's determination. Exclusion criteria during initial screening included (1) a history of substance dependence or substance abuse during the 6 months prior to participation, (2) a currently unstable clinical disorder or severe general medical disorder, or (3) a history of head injury, multiple seizures, or concussions resulting in unconsciousness for more than $30 \mathrm{~min}$. Table 1 presents demographic information for the three participant groups.

\section{WERC Screening Forms}

Participants completed three screening forms: the WERCAP Screen, the Stress Screen (22), and the Substance Screen. These forms are available for public use (http://werc.wustl.edu/home/ screeninginstruments).

The WERCAP Screen assesses risk of BPD and psychosis based on a quantification of lifetime symptom burden. The WERCAP Screen consists of a total of 16 questions, the first half of which are designed to assess affective symptoms experienced by individuals, while the remaining questions assess risk of psychosis. The majority of questions (10 out of 16) require two responses, including a rating of the frequency of symptom occurrence, and if present, the severity of the associated functional impairment. For the item probing into decreased need for sleep, respondents were asked to rate symptom duration rather than degree of functional impairment. Six questions in the affectivity section assess only symptom frequency, since they

TABLE 1 | Demographics for each diagnostic group.

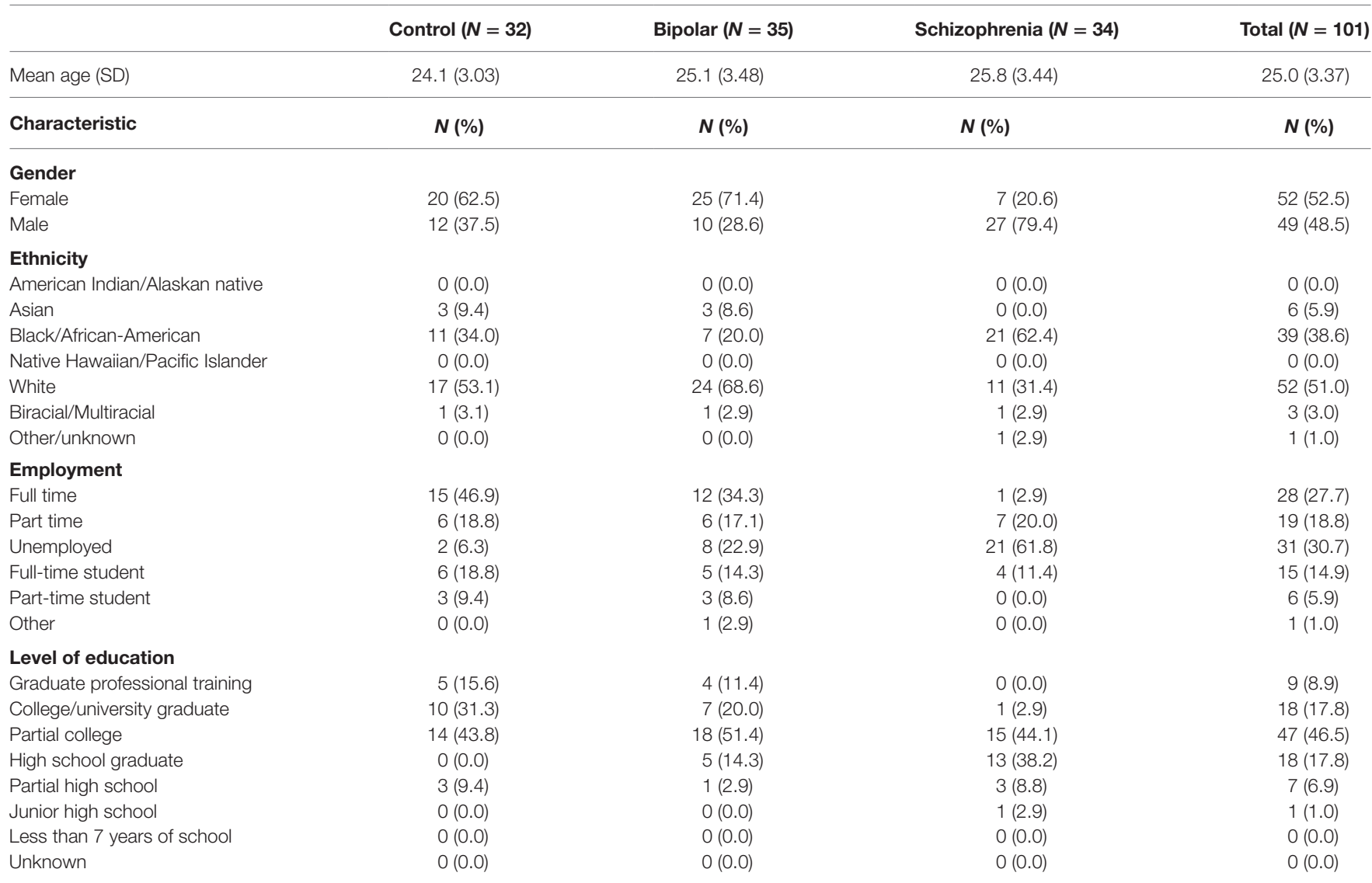


inquire about symptoms that do not typically impair function, or the degree of resulting dysfunction is difficult to assess. The responses were converted into numerical values as follows: No $=0$, Once $=1$, Rarely $(<$ yearly $)=2$, Sometimes $(>$ yearlymonthly $)=3$, Often $(>$ monthly-weekly $)=4$, and Almost Always $(>$ weekly-daily $)=5$. For items assessing effect on functionality, responses were converted as follows: Not at All $=0, \mathrm{~A}$ Little $=1$, Moderately $=2$, Severely $=3$. The frequency and functionality scores for items 1-8 were summed to generate a composite aWERCAP (affectivity) score, and the remaining items (9-16) were summed to generate the composite pWERCAP (psychosis) score. The maximum aWERCAP score possible is 49 , and the maximum pWERCAP score is 64 , yielding a maximum total WERCAP Screen score of 113.

The Stress Screen assesses the total stress burden of 23 common psychosocial stressors, such as one's relationships with family and friends, substance use, or the workplace [see Ref. (22) for a complete list]. Space is also provided to write in up to two additional stressors. By default, the Stress Screen is designed to capture the current stress load on an individual. Respondents are asked to rate the extent to which they are affected by each stressor by marking the appropriate checkbox. Each response is converted to a numerical rating $(\mathrm{No}=0, \mathrm{~A}$ Little $=1$, Moderate $=2$, A Lot $=5$, Severely $=10$ ), and then summed to generate the Stress Screen score. The maximum Stress Screen score possible is 230 .

The Substance Screen is a 20 -item questionnaire that assesses the current substance-use habits of the respondent. Respondents were asked to rate their usage frequency of a variety of psychotropic substances, such as caffeine, nicotine, prescription drugs, etc. [see Ref. (22) for a complete list] and could also choose to write in up to two additional substances. The frequency responses were converted into a numerical score using the same scale as that in the WERCAP Screen, and then summed to generate the Substance Screen score.

\section{Data Analysis}

Statistical analyses were performed using IBM's SPSS software (IBM SPSS Statistics for Macintosh, Version 24.0, Armonk, NY, USA). Demographic differences between diagnostic groups were assessed with one-way ANOVAs treating diagnosis as a fixed factor or chi-square $\left(\chi^{2}\right)$ tests as appropriate. Betweengroup differences in aWERCAP, pWERCAP, and Stress Screen scores were examined using univariate analysis of covariance (ANCOVA) tests, including gender, age, and years of education as covariates, followed by post hoc pairwise tests, corrected for multiple comparisons treating diagnostic group as a fixed effect.

We utilized logistic regression to examine the capability of the aWERCAP, pWERCAP, WERC Stress Screen, and number of substances used to predict diagnostic group. The number of substances measured by the Substance Screen was used in the logistic regression instead of a Substance Screen score derived from summing all substance usage frequencies, due to substantial potency variability of the different substances. Only the most prevalent substances used by our participants were included in the logistic regression (i.e., tobacco, coffee, other caffeinated beverages, alcohol, and cannabis). Receiver Operating Characteristic
(ROC) curves were generated for aWERCAP and pWERCAP to study classification with varying thresholds and determine the thresholds with optimum sensitivity and specificity. Substance and Stress Screen scores were not predictive of diagnostic group membership in the logistic regressions and, therefore, were not considered for this analysis.

\section{RESULTS}

\section{Demographics}

Demographic information for each diagnostic group is presented in Table 1. Mean age was not significantly different between groups $\left(F_{(2,98)}=1.848, p=0.163\right)$. However, there were significant differences in gender $\left(\chi^{2}=20.122, p<0.001\right)$ and ethnicity $\left(\chi^{2}=17.465, p=0.026\right)$ between groups. Psychiatric comorbidities in each group are shown in Table 2.

\section{WERCAP Screen}

Univariate analyses showed significant group effects for aWERCAP $\left(F_{(2,92)}=52.904, p<0.001\right)$ and pWERCAP $\left(F_{(2,92)}=50.378, p<0.001, \eta^{2}=0.523\right)$, but not for stress or substance scores. The relationship between individual aWERCAP, pWERCAP, and Stress Screen scores is depicted in Figure 1. Average scores for each of the screens are shown in Table 3. Pairwise comparisons between diagnoses, Bonferroni correcting for multiple comparisons, showed that BPD had significantly higher aWERCAP scores than CON $(p<0.001)$ and SCZ $(p=0.001)$. Scores on the aWERCAP in SCZ were also higher than in CON $(p<0.001)$. pWERCAP scores were significantly higher in SCZ compared to BPD $(p<0.001)$ and CON $(p<0.001)$, as well as in BPD compared to CON $(p=0.001)$. Mean aWERCAP scores did not significantly differ between genders $(t=0.691, p=0.491)$. Mean aWERCAP item scores broken down by sex and diagnosis are shown in Figure 2. Males experienced significantly higher total psychotic symptom scores than females $(t=-2.324, p=0.022)$. Mean pWERCAP item scores for males and females in each diagnostic group are shown in Figure 3.

\section{Stress Screen}

Univariate analysis of Stress Screen scores showed a significant main effect of diagnostic group $\left(F_{(2,92)}=3.740, p=0.027\right)$. Mean Stress Screen item scores for each diagnostic group are shown in Figure 4. Pairwise comparisons showed that BPD had significantly higher Stress Screen scores than the CON $(p=0.033)$. However, BPD did not significantly differ from the SCZ on stress severity. SCZ did not significantly differ from CON on stress severity $(p=0.182)$. We found no significant differences in WERC Stress scores across genders $(t=0.541, p=0.589)$.

\section{Substance Screen}

A comparison of the rate of substance use showed only a marginal effect of diagnosis $\left(F_{(2,92)}=2.987, p=0.055\right)$. BPD reported using significantly more substances than CON $(p=0.015)$ or SCZ $(p=0.032)$. There was no significant difference in the number of substances used between the CON and SCZ. SCZ reported tobacco use at significantly higher rates than CON $(p=0.021)$. 
TABLE 2 | Prevalence of psychiatric disorders for each diagnostic group $(N=101)$.

\begin{tabular}{|c|c|c|c|c|}
\hline & Control $(N=32)$ & Bipolar $(N=35)$ & Schizophrenia $(N=34)$ & Total $(N=101)$ \\
\hline Psychiatric diagnosis & $N(\%)$ & $N(\%)$ & $N(\%)$ & $N(\%)$ \\
\hline No diagnosis & $30(93.8)$ & $1(2.9)$ & $0(0)$ & $31(30.7)$ \\
\hline Mood disorders & $2(6.25)$ & 33 (94.3) & $0(0)$ & $35(34.7)$ \\
\hline Major depressive disorder & $2(6.25)$ & $0(0)$ & $0(0)$ & $2(2.0)$ \\
\hline Bipolar disorder & $0(0)$ & $33(94.3)$ & $0(0)$ & $33(32.7)$ \\
\hline Anxiety disorders & $0(0)$ & $30(85.7)$ & $19(55.9)$ & $49(48.5)$ \\
\hline Generalized anxiety disorder & $0(0)$ & $3(8.6)$ & $5(14.7)$ & $8(7.9)$ \\
\hline Panic disorder & $0(0)$ & $2(5.7)$ & $1(2.9)$ & $3(3.0)$ \\
\hline Panic disorder w/agoraphobia & $0(0)$ & $0(0)$ & $3(8.8)$ & $3(3.0)$ \\
\hline Agoraphobia w/o panic disorder & $0(0)$ & $4(11.4)$ & $5(14.7)$ & $9(8.9)$ \\
\hline PTSD & $0(0)$ & $7(20.0)$ & $4(11.8)$ & $11(10.9)$ \\
\hline Social phobia & $0(0)$ & $10(28.6)$ & $2(5.9)$ & $12(11.9)$ \\
\hline Specific phobia & $0(0)$ & $4(11.4)$ & $2(5.9)$ & $6(5.9)$ \\
\hline Obsessive compulsive disorders & $0(0)$ & $0(0)$ & $1(2.9)$ & $1(1.0)$ \\
\hline Obsessive compulsive disorder & $0(0)$ & $0(0)$ & $1(2.9)$ & $1(1.0)$ \\
\hline Body dysmorphic disorder & $0(0)$ & $0(0)$ & $0(0)$ & $4(4.0)$ \\
\hline Personality disorders & $0(0)$ & $22(62.9)$ & $9(26.5)$ & $31(30.7)$ \\
\hline Borderline PD & $0(0)$ & 5 (14.3) & $2(5.9)$ & 7 (6.9) \\
\hline Avoidant PD & $0(0)$ & $8(22.9)$ & $4(11.8)$ & $12(11.9)$ \\
\hline Schizotypal PD & $0(0)$ & $0(0)$ & $1(2.9)$ & $1(1.0)$ \\
\hline Obsessive compulsive PD & $0(0)$ & $5(14.3)$ & $1(2.9)$ & $6(5.9)$ \\
\hline Antisocial PD & $0(0)$ & $1(2.9)$ & $0(0)$ & $1(1.0)$ \\
\hline Dependent PD & $0(0)$ & $3(8.6)$ & $1(2.9)$ & $4(4.0)$ \\
\hline Paranoid PD & $0(0)$ & 5 (14.3) & $4(11.8)$ & $9(8.9)$ \\
\hline Narcissistic PD & $0(0)$ & $3(8.6)$ & $1(2.9)$ & $4(4.0)$ \\
\hline Psychotic disorders & $0(0)$ & $1(2.9)$ & $34(100.0)$ & $35(34.7)$ \\
\hline Schizoaffective disorder & $0(0)$ & $1(2.9)$ & $4(11.8)$ & $5(5.0)$ \\
\hline Schizophrenia & $0(0)$ & $0(0)$ & $29(85.3)$ & $29(28.7)$ \\
\hline Psychosis NOS & $0(0)$ & $0(0)$ & $1(2.9)$ & $1(1.0)$ \\
\hline Substance-related disorders & $0(0)$ & $0(0)$ & $2(5.9)$ & $2(2.0)$ \\
\hline Cannabis abuse & $0(0)$ & $1(2.9)$ & $2(5.9)$ & $3(3.0)$ \\
\hline Cannabis dependence & $0(0)$ & $0(0)$ & $0(0)$ & $0(0.0)$ \\
\hline Alcohol abuse & $0(0)$ & $0(0)$ & $0(0)$ & $0(0.0)$ \\
\hline Alcohol dependence & $0(0)$ & $0(0)$ & $0(0)$ & $0(0.0)$ \\
\hline Opioid dependence & $0(0)$ & $0(0)$ & $0(0)$ & $0(0.0)$ \\
\hline Polysubstance abuse & $0(0)$ & $0(0)$ & $0(0)$ & $0(0.0)$ \\
\hline Hallucinogen dependence & $0(0)$ & $0(0)$ & $0(0)$ & $0(0.0)$ \\
\hline Stimulant dependence & $0(0)$ & $0(0)$ & $0(0)$ & $0(0.0)$ \\
\hline Eating disorders & $0(0)$ & $2(5.7)$ & $0(0)$ & $2(2.0)$ \\
\hline Bulimia nervosa & $0(0)$ & $1(2.9)$ & $0(0)$ & $1(1.0)$ \\
\hline Binge eating disorder & $0(0)$ & $1(2.9)$ & $0(0)$ & $1(1.0)$ \\
\hline
\end{tabular}

BPD had significantly higher coffee consumption rates than SCZ $(p=0.02)$. We found no significant differences in the rates of substance use as measured by the WERC Substance Screen $(t=1.117, p=0.267)$.

\section{Logistic Regression - Predicting Diagnostic Group}

Overall, logistic regression models using the aWERCAP, pWERCAP, Stress Screen, and number of substances used as predictors correctly predicted diagnosis in $89.1 \%$ of participants. Specifically, the model correctly predicted $93.8 \%$ of CON, $85.7 \%$ of BPD, and $88.2 \%$ of SCZ. However, only the aWERCAP $\left(\chi^{2}=47.835\right.$, $p<0.001)$ and pWERCAP $\left(\chi^{2}=79.974, p<0.001\right)$ scores were useful predictors of diagnostic category, whereas the Stress Screen $\left(\chi^{2}=2.587, p=0.274\right)$ and number of substances used $\left(\chi^{2}=2.918, p=0.232\right)$ did not significantly contribute to group prediction. Only the aWERCAP score significantly predicted
BPD $(p<0.001)$, and only the pWERCAP score significantly predicted SCZ $(p=0.001)$. Results of the logistic regression are presented in Table 4.

\section{ROC Curves for WERCAP}

To evaluate the discriminative power of the WERCAP screen to detect BPD and SCZ, ROC curves were calculated for aWERCAP and pWERCAP (see Figure 5). For detecting BPD, aWERCAP performed significantly better than chance, with an area under the curve (AUC) of 0.873 ( $p<0.001)$; however, pWERCAP was not significantly better than chance at detecting BPD $(\mathrm{AUC}=0.524$, $p=0.695$ ). The optimal cutoff on the aWERCAP to identify BPD was 20 (Table 5). At this cut point, sensitivity was 0.91 and specificity was 0.71 .

For detecting SCZ, pWERCAP demonstrated an AUC of 0.894 $(p<0.001)$, indicating that $\mathrm{pWERCAP}$ has very good discrimination for SCZ. aWERCAP was not significantly better than chance 


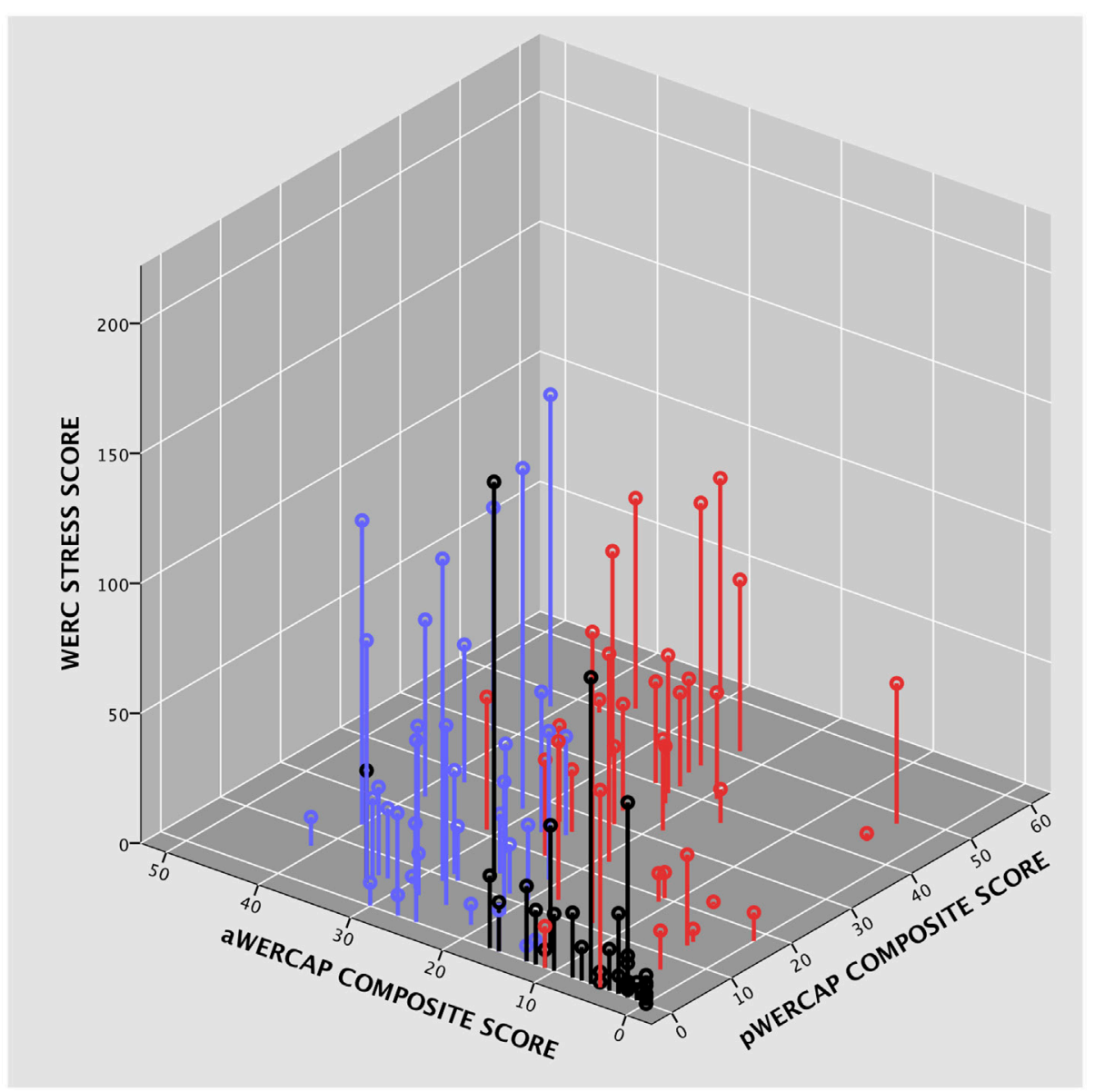

Control

Bipolar

Schizophrenia

FIGURE 1 | 3D scatter-plot showing Stress Screen scores, aWERCAP composite scores, and pWERCAP composite scores in each diagnostic group

TABLE 3 | Mean (SD) WERC Screen scores and number of substances used in each diagnostic category.

\begin{tabular}{lccc}
\hline & Control & Bipolar & Schizophrenia \\
\hline Stress Screen & $24(34)$ & $46(37)$ & $39(28)$ \\
Number of substances & $3.3(0.4)$ & $4.7(0.4)$ & $3.4(0.4)$ \\
aWERCAP & $7.1(8.1)$ & $29.2(7.8)$ & $19.0(11.0)$ \\
pWERCAP & $0.8(3.1)$ & $13.2(12.3)$ & $31.8(16.8)$ \\
\hline
\end{tabular}

at detecting SCZ (AUC $=0.504, p=0.951)$. The optimal cutoff on the pWERCAP to identify SCZ in this study population was 13 (Table 5). At this cut point, sensitivity was 0.88 and specificity was 0.82 .

\section{DISCUSSION}

A goal of this study was to test whether the WERC questionnaires could reliably identify participants with BPD and SCZ. We first investigated performance on these questionnaires by participants with these diagnoses and controls. There was a significant main effect of diagnosis for WERCAP scores, stress severity, and the number of substances used. As we predicted, individuals with
BPD scored significantly higher on the affective symptoms (aWERCAP) than the control or SCZ groups. The SCZ group, however, had higher affective symptoms than controls, consistent with the increased affective symptoms (primarily depressive symptoms) often seen in SCZ patients (70-76). Both of our patient groups also had higher psychotic symptoms (pWERCAP) than the control group, with the SCZ patients having the most severe symptoms. The BPD group, however, reported the most significant psychosocial stress severity, as well as the most substances used. This is consistent with results from previous studies showing BPD with a higher prevalence of substance-use disorders (SUDs) than any other psychiatric disorder (77). A high Stress Screen score may not necessarily indicate greater stress reactivity to everyday stressors. Higher sensitivity to stress has been associated with psychosis risk (78-80) and also has been reported in SCZ (81) as well as BPD (82). In addition, several reports have associated childhood adversity with risk of psychosis $(58,83)$, suggesting the importance of documenting lifetime stressors. Abnormalities in the hypothalamic-pituitary-adrenal axis, a key mediator of the stress response, have been implicated in both SCZ $(84)$ and BPD $(85,86)$. Stress hypersensitivity and psychosocial stress increase susceptibility to SCZ $(87,88)$ and $\operatorname{BPD}(89,90)$ 


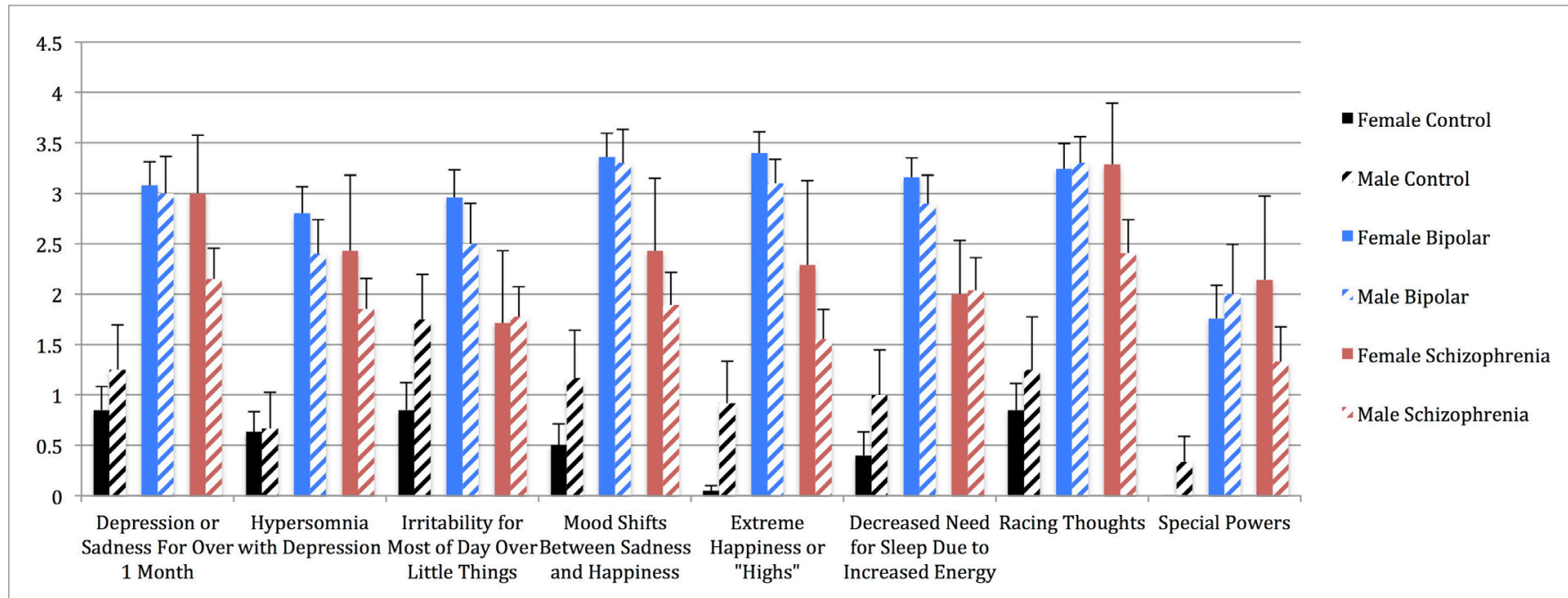

FIGURE 2 | Mean aWERCAP Screen individual item scores (frequency) in males vs. females of each diagnostic group, with standard error bars. $x$-axis $=$ individual aWERCAP items, $y$-axis = mean aWERCAP frequency score, derived by summing and averaging the frequency responses in the affectivity section.

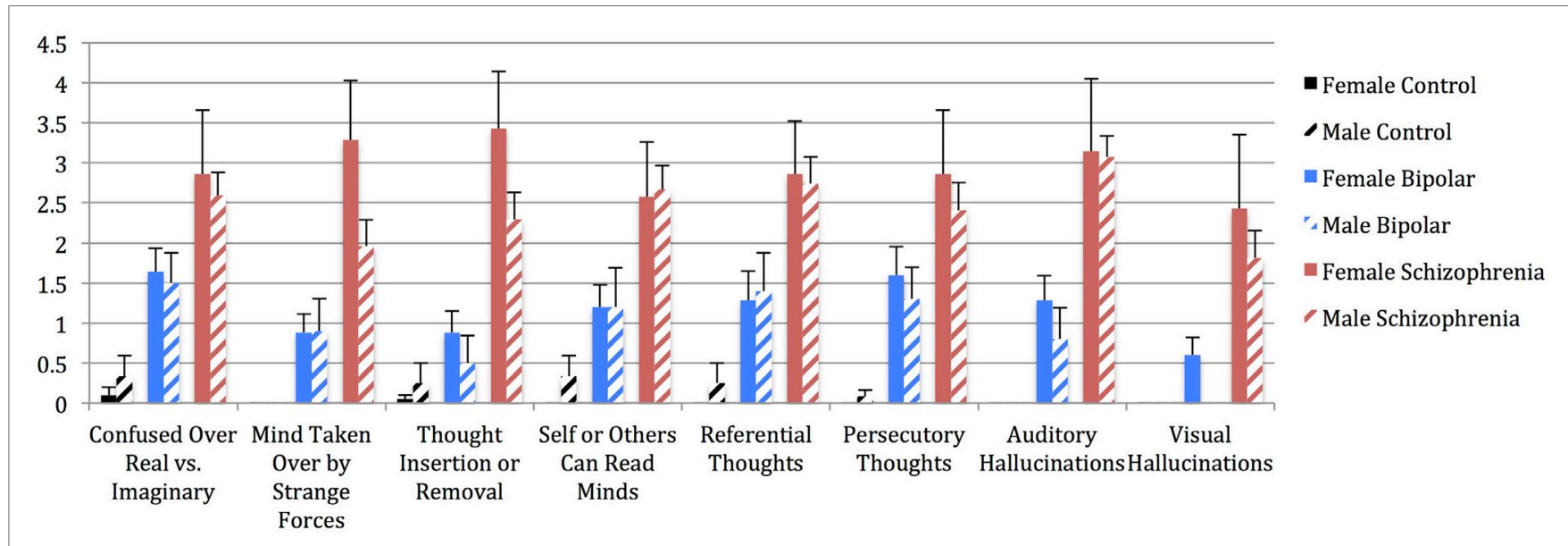

FIGURE 3 | Mean pWERCAP Screen individual item scores (frequency) in males vs. females of each diagnostic group, with standard error bars. $x$-axis $=$ individual pWERCAP items, $y$-axis = mean pWERCAP frequency score, derived by summing and averaging the frequency responses in the psychosis section.

and also exacerbate symptoms in both disorders (91). Index manic (69) and psychotic (92) episodes are often preceded by an increase in stressful life events. Thus, the WERCAP Stress Screen may be a useful tool for schools and clinics in monitoring at-risk individuals to prevent onset or relapse.

The affectivity (aWERCAP) score alone identified individuals with BPD in our sample with high sensitivity and specificity, suggesting that the aWERCAP may be useful for detecting BPD in larger settings. Our current findings indicated a minimum aWERCAP cutoff score of 20 for detection of BPD diagnosis, below which an individual would be unlikely to have this diagnosis. Higher scores, however, do not necessarily imply a diagnosis of BPD, as there are likely other conditions that could be associated with severe affective symptoms. While not addressed in the current study, it is plausible, for example, that individuals with certain personality disorders that involve mood lability, such as borderline personality disorder, may report high aWERCAP scores. Depressive disorders may also sometimes be associated with mood lability or irritability, although the majority of the aWERCAP question items would be unlikely to be endorsed by affected individuals. It is, therefore, expected that the aWERCAP alone would result in high false positive rates for BPD in community surveys, and would be insufficient to identify affected individuals. However, the aWERCAP may be suitable as an initial screening tool that would identify individuals who may require clinical or structured assessments.

For the pWERCAP, a cutoff score of 13 was associated with $88 \%$ sensitivity, $82 \%$ specificity, $83 \%$ PPV, and $87 \%$ negative predictive value for SCZ diagnosis in our study sample. This score seemed 


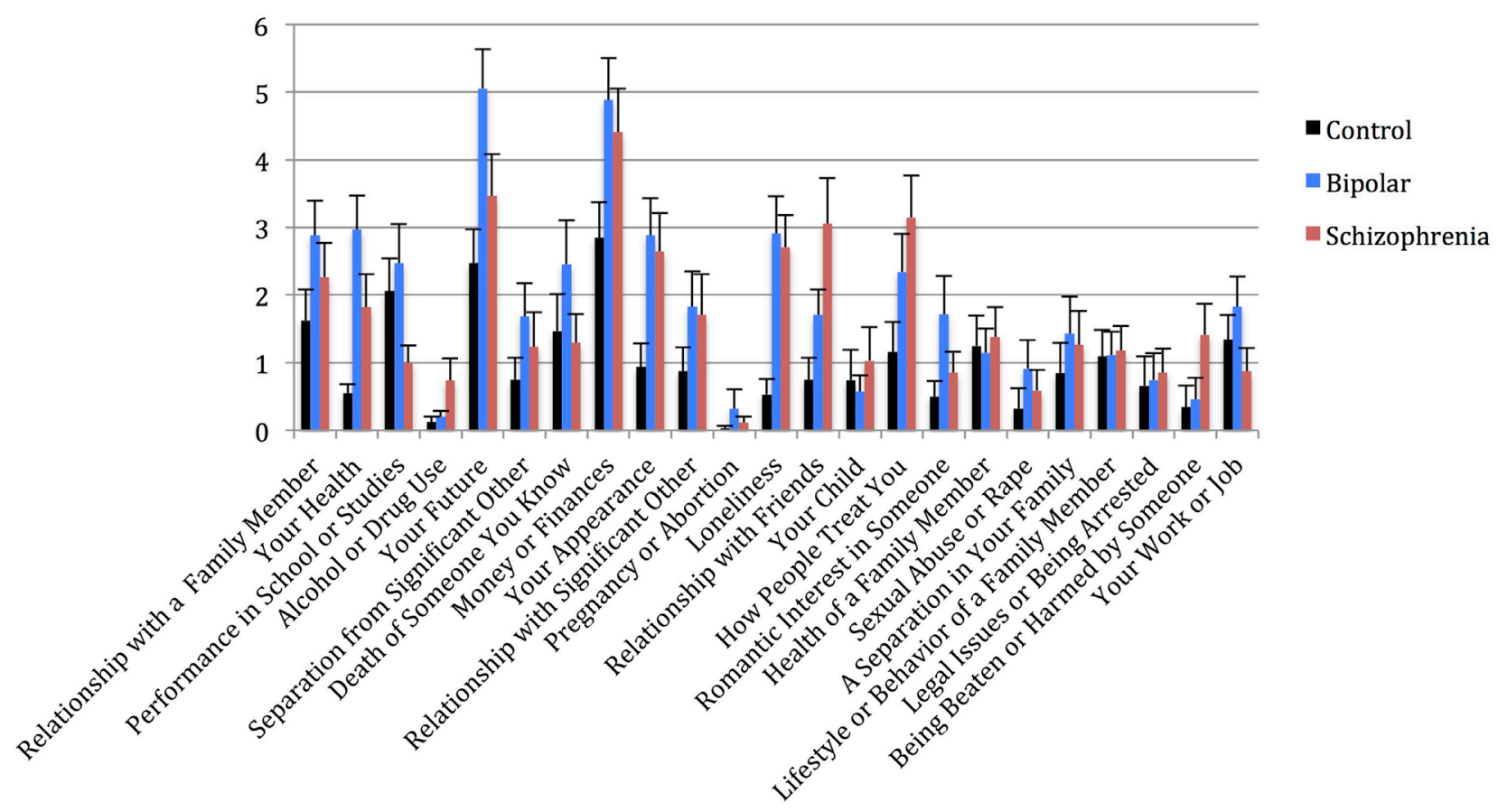

FIGURE 4 | Mean WERCAP Stress Screen individual item scores in each diagnostic group, with standard error bars. $x$-axis = individual Stress Screen items, $y$-axis $=$ mean Stress Screen scores for each item.

TABLE 4 | Logistic regression analysis of WERC Screens for diagnosis, with control or schizophrenia group as reference category.

\begin{tabular}{|c|c|c|c|c|c|c|}
\hline Predictor & $\boldsymbol{\beta}$ & SE $\beta$ & Wald's $\chi^{2}$ & df & $p$ & $e^{\beta}$ (odds ratio) \\
\hline \multicolumn{7}{|l|}{ Bipolar disordera } \\
\hline Constant & -6.446 & 1.721 & 14.033 & 1 & $<0.001$ & \\
\hline aWERCAP & 0.279 & 0.078 & 12.956 & 1 & $<0.001$ & 1.322 \\
\hline pWERCAP & 0.282 & 0.165 & 2.915 & 1 & 0.134 & 1.326 \\
\hline WERC stress & -0.028 & 0.018 & 2.241 & 1 & 0.973 & 0.973 \\
\hline Substances used & 0.343 & 0.222 & 2.390 & 1 & 0.122 & 1.409 \\
\hline \multicolumn{7}{|l|}{ Schizophrenia ${ }^{a}$} \\
\hline Constant & -2.310 & 1.210 & 3.647 & 1 & 0.056 & \\
\hline aWERCAP & -0.074 & 0.083 & 0.802 & 1 & 0.370 & 0.928 \\
\hline pWERCAP & 0.520 & 0.170 & 9.358 & 1 & 0.002 & 1.682 \\
\hline WERC stress & -0.020 & 0.020 & 1.038 & 1 & 0.308 & 0.980 \\
\hline Substances used & 0.107 & 0.281 & 0.146 & 1 & 0.702 & 1.113 \\
\hline \multicolumn{7}{|l|}{ Bipolar disorder } \\
\hline Constant & -4.136 & 1.683 & 6.042 & 1 & 0.014 & \\
\hline aWERCAP & 0.353 & 0.096 & 13.521 & 1 & $<0.001$ & 1.424 \\
\hline pWERCAP & -0.237 & 0.063 & 14.073 & 1 & $<0.001$ & 0.789 \\
\hline WERC stress & -0.007 & 0.013 & 0.297 & 1 & 0.583 & 0.993 \\
\hline Substances used & 0.236 & 0.246 & 0.914 & 1 & 339 & 1.266 \\
\hline Test & & & $\chi^{2}$ & df & $p$ & \\
\hline \multicolumn{7}{|l|}{ Overall model evaluation } \\
\hline Likelihood ratio test & & & 156.555 & 8 & $<0.001$ & \\
\hline \multicolumn{7}{|l|}{ Goodness-of-fit test } \\
\hline Pearson & & & 153.307 & 190 & 0.976 & \\
\hline
\end{tabular}

${ }^{a}$ Results of multinomial logistic regression predicting diagnosis. Cox and Snell $R^{2}=0.78$, Nagelkerke $R^{2}=0.886, M c F a d d e n ~ R^{2}=0.706$. Healthy controls were treated as the reference group in the above analysis.

${ }^{b}$ Schizophrenia was treated as the reference category in the above analysis for comparison against the bipolar group.

low, considering that in our previous study (22), a score of $>30$ was found to best correlate with risk for developing a psychotic disorder using a gold standard of psychosis-risk assessment.
Thus, a higher score would be expected in SCZ patients. One explanation for this discrepancy is that our study population was largely medicated and stable and, therefore, would exhibit milder 


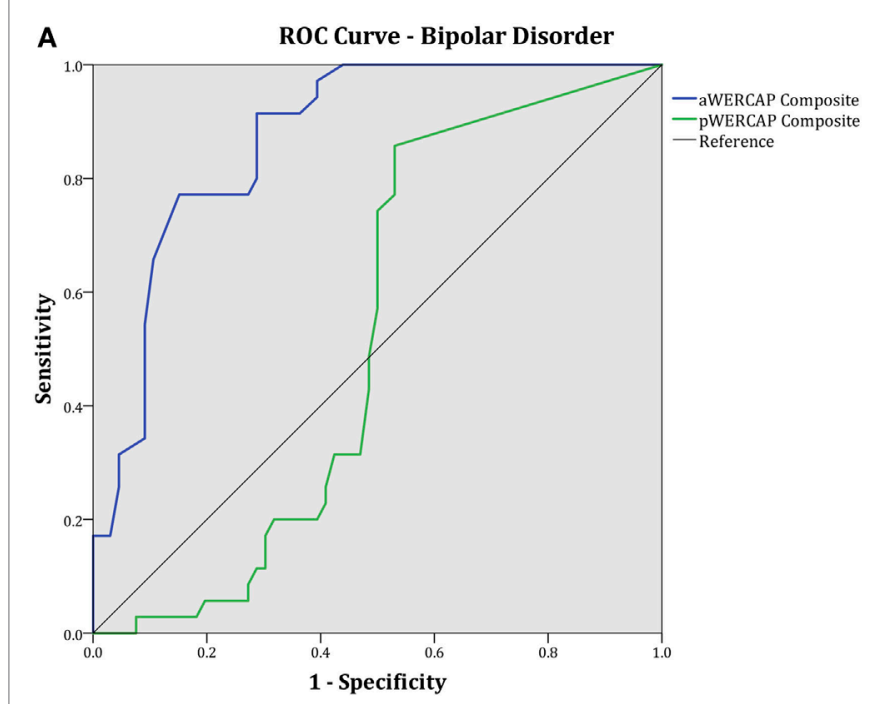

B

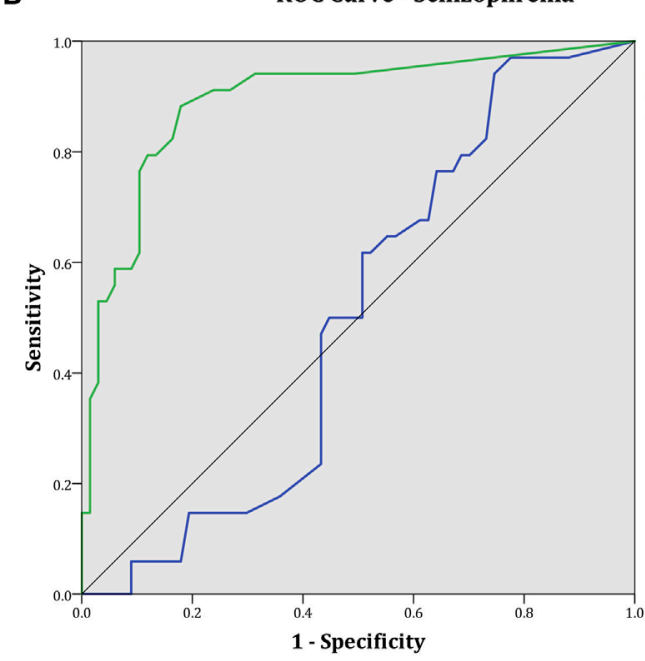

— aWERCAP Composite - pWERCAP Composite

schizophrenia.

TABLE 5 | ROC curve analysis for WERCAP and diagnosis.

\begin{tabular}{|c|c|c|c|c|c|c|c|c|}
\hline \multirow[t]{2}{*}{ Cutoff } & \multicolumn{2}{|c|}{ Sensitivity } & \multicolumn{2}{|c|}{ Specificity } & \multicolumn{2}{|c|}{ PPV } & \multicolumn{2}{|c|}{ NPV } \\
\hline & aWERCAP & pWERCAP & aWERCAP & pWERCAP & aWERCAP & pWERCAP & aWERCAP & pWERCAP \\
\hline 0 & 100.00 & 100.00 & 0.00 & 0.00 & 50.0 & 50.0 & $\mathrm{n} / \mathrm{a}$ & $\mathrm{n} / \mathrm{a}$ \\
\hline 1 & 100.00 & 94.00 & 14.00 & 51.00 & 54.0 & 65.7 & 100.0 & 89.5 \\
\hline 2 & 100.00 & 94.00 & 15.00 & 51.00 & 54.0 & 65.7 & 100.0 & 89.5 \\
\hline 3 & 100.00 & 94.00 & 24.00 & 51.00 & 57.0 & 65.7 & 100.0 & 89.5 \\
\hline 4 & 100.00 & 94.00 & 29.00 & 55.00 & 58.0 & 67.6 & 100.0 & 90.2 \\
\hline 5 & 100.00 & 94.00 & 36.00 & 60.00 & 61.0 & 70.1 & 100.0 & 90.9 \\
\hline 6 & 100.00 & 94.00 & 41.00 & 64.00 & 63.0 & 72.3 & 100.0 & 91.4 \\
\hline 7 & 100.00 & 94.00 & 42.00 & 69.00 & 63.0 & 75.2 & 100.0 & 92.0 \\
\hline 8 & 100.00 & 91.00 & 45.00 & 73.00 & 65.0 & 77.1 & 100.0 & 89.0 \\
\hline 9 & 100.00 & 91.00 & 47.00 & 73.00 & 65.0 & 77.1 & 100.0 & 89.0 \\
\hline 10 & 100.00 & 91.00 & 47.00 & 75.00 & 65.0 & 78.4 & 100.0 & 89.3 \\
\hline 11 & 100.00 & 91.00 & 48.00 & 76.00 & 66.0 & 79.1 & 100.0 & 89.4 \\
\hline 12 & 100.00 & 88.00 & 55.00 & 82.00 & 69.0 & 83.0 & 100.0 & 87.2 \\
\hline 13 & 100.00 & 88.00 & 56.00 & 82.00 & 69.0 & 83.0 & 100.0 & 87.2 \\
\hline 14 & 97.00 & 82.00 & 61.00 & 84.00 & 71.0 & 83.7 & 95.0 & 82.4 \\
\hline 15 & 94.00 & 79.00 & 61.00 & 87.00 & 71.0 & 85.9 & 91.0 & 80.6 \\
\hline 16 & 94.00 & 79.00 & 61.00 & 87.00 & 71.0 & 87.0 & 91.0 & 81.0 \\
\hline 17 & 91.00 & 79.00 & 64.00 & 88.00 & 72.0 & 88.0 & 88.0 & 81.00 \\
\hline 19 & 91.00 & 76.00 & 67.00 & 90.00 & 73.0 & 88.4 & 88.0 & 78.9 \\
\hline 20 & 91.00 & 74.00 & 71.00 & 90.00 & 76.0 & 88.1 & 89.0 & 77.6 \\
\hline 21 & 86.00 & 68.00 & 71.00 & 90.0 & 75.0 & 87.0 & 84.0 & 74.0 \\
\hline 22 & 80.00 & 65.00 & 71.00 & 90.0 & 73.0 & 87.0 & 78.0 & 72.0 \\
\hline 23 & 77.00 & 62.00 & 73.00 & 90.0 & 74.0 & 86.0 & 76.0 & 70.0 \\
\hline 25 & 77.00 & 59.00 & 85.00 & 93.00 & 84.0 & 89.4 & 79.0 & 69.4 \\
\hline 26 & 66.00 & 59.00 & 89.00 & 94.00 & 86.0 & 91.0 & 72.0 & 70.0 \\
\hline 30 & 40.00 & 53.00 & 91.00 & 97.00 & 82.0 & 94.6 & 60.0 & 67.4 \\
\hline 35 & 17.00 & 44.00 & 97.00 & 97.00 & 85.0 & 93.6 & 54.0 & 63.4 \\
\hline 40 & 11.00 & 35.00 & 100.00 & 99.00 & 100.0 & 97.2 & 53.0 & 60.4 \\
\hline 45 & 0.00 & 18.00 & 100.00 & 99.00 & $\mathrm{n} / \mathrm{a}$ & 94.7 & 50.0 & 54.7 \\
\hline
\end{tabular}

Values shown reflect the aWERCAP's predictive capability of bipolar disorder and the pWERCAP's ability to predict schizophrenia. Bolded figures indicate values associated with recommended cutoff points.

symptoms than untreated patients or individuals. Although the WERCAP Screen was intended to elicit chronic or lifetime symptoms, it is plausible that individuals who have been psychiatrically stable could nevertheless underestimate their symptom severity. Thus, we believe that a score of 13 may be too conservative a cutoff in community settings, and would likely identify individuals 
without any significant psychopathology. Psychotic-like experiences are relatively common, especially at younger ages, and most with such experiences never develop psychotic disorders (93-96). For screening individuals with psychotic disorders in an unmedicated population, a higher cutoff score would, therefore, likely be more specific.

Contrary to our hypothesis, the Stress Screen score and number of common substances (tobacco, coffee, other caffeinated beverages, alcohol, and cannabis) were not significant predictors of diagnostic category, suggesting that these characteristics are non-specific to psychiatric diagnoses. This is not entirely surprising, as multiple other psychiatric disorders, including depression, anxiety, and externalizing disorders have been associated with psychosocial stress $(97,98)$ and substance use $(99,100)$. With regard to substance-use assessment, it should be noted that the Substance Screen by default captures current substance-use frequency. It is, thus, conceivable that lifetime exposure to specific substances would be more predictive of BPD or SCZ than recent exposure. Diagnoses of SUDs frequently precede onset of SCZ and BPD (24). Certain substances are specifically associated with symptom onset or exacerbation. For example, cannabis use increases the risk of subsequent mania (101) and psychosis (102). Substance use has also been associated with earlier onset of mania $(36,103)$ and psychosis (104). A meta-analysis found that cannabis and unspecified substance use significantly increased age of onset of psychosis by 2.70 and 2.00 years, respectively, compared to non-substance-using controls (105). Substance abuse has also been reported to predict conversion to psychosis in a population at high clinical risk (106).

Our study provides an initial investigation of the utility of three recently developed screening instruments in identifying SCZ and BPD. Accurately diagnosing these medical disorders would, however, continue to require clinical or structured assessments, as established diagnostic criteria are complex, often involving multiple symptom categories (e.g., positive, negative, and disorganization symptoms for SCZ), specific duration of symptoms, and diagnostic exclusions $(107,108)$; thus, screening questionnaires should not be expected to be sufficient for

\section{REFERENCES}

1. Whiteford HA, Degenhardt L, Rehm J, Baxter AJ, Ferrari AJ, Erskine HE, et al. Global burden of disease attributable to mental and substance use disorders: findings from the Global Burden of Disease Study 2010. Lancet (2013) 382(9904):1575-86. doi:10.1016/S0140-6736(13)61611-6

2. Penttila M, Jaaskelainen E, Hirvonen N, Isohanni M, Miettunen J. Duration of untreated psychosis as predictor of long-term outcome in schizophrenia: systematic review and meta-analysis. Br J Psychiatry (2014) 205(2):88-94. doi:10.1192/bjp.bp.113.127753

3. Cechnicki A, Cichocki L, Kalisz A, Bladzinski P, Adamczyk P, Franczyk-Glita J. Duration of untreated psychosis (DUP) and the course of schizophrenia in a 20-year follow-up study. Psychiatry Res (2014) 219(3):420-5. doi:10.1016/j. psychres.2014.05.046

4. Ran MS, Weng X, Chan CL, Chen EY, Tang CP, Lin FR, et al. Different outcomes of never-treated and treated patients with schizophrenia: 14-year follow-up study in rural China. Br J Psychiatry (2015) 207(6):495-500. doi:10.1192/bjp.bp.114.157685

5. Cohen A, Patel V, Thara R, Gureje O. Questioning an axiom: better prognosis for schizophrenia in the developing world? Schizophr Bull (2008) 34(2):229-44. doi:10.1093/schbul/sbm 105 diagnosis. Nevertheless, they can be useful for identifying individuals who may require further assessment. A limitation to our study is that it was conducted using a moderately small-sized sample. Furthermore, the study population was not representative of the community, where a wider range of psychopathologies exist which could make identifying bipolar or psychotic disorders more difficult. Thus, larger studies in diverse settings would be needed to adequately test the psychometric properties of these instruments. Nonetheless, this study demonstrates the potential of the WERC Screen as a screening tool for BPD and SCZ, especially in areas with limited access to a trained psychiatrist, or in settings where conducting a detailed interview is not feasible. Well-validated, self-report instruments could play an increasing role in mental health care in the future. There are relatively few mental health providers, with primary care providers providing a greater proportion of mental health care while faced with increasing time constraints (109). Screening for mental illness could also be useful in schools to identify individuals early when intervention could diminish the burden on the illness and improve functioning. Developing and validating improved screening tools for various aspects of psychopathology are, therefore, highly recommended.

\section{AUTHOR CONTRIBUTIONS}

DM designed and supervised the study. $\mathrm{CH}$ and DG performed analyses. $\mathrm{CH}, \mathrm{DG}$, and DM wrote the paper. All authors contributed to discussion of results and contributed to the manuscript at all stages.

\section{FUNDING}

The research was supported by NIH grant R01 MH104414, as well as the Taylor Family Institute and Center for Brain Research on Mood Disorders at the Department of Psychiatry, Washington University in St. Louis. Dr. DM has previously received grants from the NIMH, NARSAD, the McDonnell Center for Systems Neuroscience, the Taylor Family Institute, and Eli Lilly.

6. Altamura AC, Dell'Osso B, Berlin HA, Buoli M, Bassetti R, Mundo E. Duration of untreated illness and suicide in bipolar disorder: a naturalistic study. Eur Arch Psychiatry Clin Neurosci (2010) 260(5):385-91. doi:10.1007/ s00406-009-0085-2

7. Goldberg JF, Ernst CL. Features associated with the delayed initiation of mood stabilizers at illness onset in bipolar disorder. J Clin Psychiatry (2002) 63(11):985-91. doi:10.4088/JCP.v63n1105

8. Altamura AC, Buoli M, Caldiroli A, Caron L, Cumerlato Melter C, Dobrea C, et al. Misdiagnosis, duration of untreated illness (DUI) and outcome in bipolar patients with psychotic symptoms: a naturalistic study. J Affect Disord (2015) 182:70-5. doi:10.1016/j.jad.2015.04.024

9. Stensland MD, Schultz JF, Frytak JR. Diagnosis of unipolar depression following initial identification of bipolar disorder: a common and costly misdiagnosis. J Clin Psychiatry (2008) 69(5):749-58. doi:10.4088/JCP.v69n0508

10. Keck PE Jr, Kessler RC, Ross R. Clinical and economic effects of unrecognized or inadequately treated bipolar disorder. J Psychiatr Pract (2008) 14(Suppl 2):31-8. doi:10.1097/01.pra.0000320124.91799.2a

11. Prien RF, Klett CJ, Caffey EM Jr. Lithium carbonate and imipramine in prevention of affective episodes. A comparison in recurrent affective illness. Arch Gen Psychiatry (1973) 29(3):420-5. doi:10.1001/archpsyc.1973. 04200030104017 
12. Drancourt N, Etain B, Lajnef M, Henry C, Raust A, Cochet B, et al. Duration of untreated bipolar disorder: missed opportunities on the long road to optimal treatment. Acta Psychiatr Scand (2013) 127(2):136-44. doi:10.1111/j.1600-0447.2012.01917.x

13. Altman EG, Hedeker D, Peterson JL, Davis JM. The Altman SelfRating Mania Scale. Biol Psychiatry (1997) 42(10):948-55. doi:10.1016/ S0006-3223(96)00548-3

14. Young RC, Biggs JT, Ziegler VE, Meyer DA. A rating scale for mania: reliability, validity and sensitivity. Br J Psychiatry (1978) 133:429-35. doi:10.1192/ bjp.133.5.429

15. Nassir Ghaemi S, Miller CJ, Berv DA, Klugman J, Rosenquist KJ, Pies RW. Sensitivity and specificity of a new bipolar spectrum diagnostic scale. J Affect Disord (2005) 84(2-3):273-7. doi:10.1016/S0165-0327(03)00196-4

16. Miller CJ, Johnson SL, Kwapil TR, Carver CS. Three studies on self-report scales to detect bipolar disorder. J Affect Disord (2011) 128(3):199-210. doi:10.1016/j.jad.2010.07.012

17. Zimmerman M, Galione JN, Ruggero CJ, Chelminski I, Dalrymple K, Young D. Are screening scales for bipolar disorder good enough to be used in clinical practice? Compr Psychiatry (2011) 52(6):600-6. doi:10.1016/j. comppsych.2011.01.004

18. Zimmerman M, Galione JN, Chelminski I, Young D, Ruggero CJ. Performance of the Bipolar Spectrum Diagnostic Scale in psychiatric outpatients. Bipolar Disord (2010) 12(5):528-38. doi:10.1111/j.1399-5618.2010.00840.x

19. Boonstra N, Wunderink L, Sytema S, Wiersma D. Improving detection of first-episode psychosis by mental health-care services using a self-report questionnaire. Early Interv Psychiatry (2009) 3(4):289-95. doi:10.1111/j.1751-7893.2009.00147.x

20. Andreasen NC. Scale for the Assessment of Positive Symptoms (SAPS). Iowa City: University of Iowa (1984).

21. Kay SR, Fiszbein A, Opler LA. The positive and negative syndrome scale (PANSS) for schizophrenia. Schizophr Bull (1987) 13(2):261-76. doi:10.1093/ schbul/13.2.261

22. Mamah D, Owoso A, Sheffield JM, Bayer C. The WERCAP screen and the WERC stress screen: psychometrics of self-rated instruments for assessing bipolar and psychotic disorder risk and perceived stress burden. Compr Psychiatry (2014) 55(7):1757-71. doi:10.1016/j.comppsych.2014.07.004

23. Holtzman CW, Trotman HD, Goulding SM, Ryan AT, Macdonald AN, Shapiro DI, et al. Stress and neurodevelopmental processes in the emergence of psychosis. Neuroscience (2013) 249:172-91. doi:10.1016/j. neuroscience.2012.12.017

24. Andersen SM, Randers A, Jensen CM, Bisgaard C, Steinhausen HC. Preceding diagnoses to young adult bipolar disorder and schizophrenia in a nationwide study. BMC Psychiatry (2013) 13:343. doi:10.1186/1471-244X-13-343

25. Gurillo P, Jauhar S, Murray RM, MacCabe JH. Does tobacco use cause psychosis? Systematic review and meta-analysis. Lancet Psychiatry (2015) 2(8):718-25. doi:10.1016/S2215-0366(15)00152-2

26. Myles N, Newall HD, Curtis J, Nielssen O, Shiers D, Large M. Tobacco use before, at, and after first-episode psychosis: a systematic meta-analysis. J Clin Psychiatry (2012) 73(4):468-75. doi:10.4088/JCP.11r07222

27. Agrawal A, Nurnberger JI Jr, Lynskey MT, Bipolar Genome S. Cannabis involvement in individuals with bipolar disorder. Psychiatry Res (2011) 185(3):459-61. doi:10.1016/j.psychres.2010.07.007

28. Moore TH, Zammit S, Lingford-Hughes A, Barnes TR, Jones PB, Burke $\mathrm{M}$, et al. Cannabis use and risk of psychotic or affective mental health outcomes: a systematic review. Lancet (2007) 370(9584):319-28. doi:10.1016/ S0140-6736(07)61162-3

29. Leeson VC, Harrison I, Ron MA, Barnes TR, Joyce EM. The effect of cannabis use and cognitive reserve on age at onset and psychosis outcomes in firstepisode schizophrenia. Schizophr Bull (2012) 38(4):873-80. doi:10.1093/ schbul/sbq153

30. Kelley ME, Wan CR, Broussard B, Crisafio A, Cristofaro S, Johnson S, et al. Marijuana use in the immediate 5-year premorbid period is associated with increased risk of onset of schizophrenia and related psychotic disorders. Schizophr Res (2016) 171(1-3):62-7. doi:10.1016/j.schres.2016.01.015

31. Compton MT, Kelley ME, Ramsay CE, Pringle M, Goulding SM, Esterberg ML, et al. Association of pre-onset cannabis, alcohol, and tobacco use with age at onset of prodrome and age at onset of psychosis in firstepisode patients. Am J Psychiatry (2009) 166(11):1251-7. doi:10.1176/appi. ajp.2009.09030311
32. Helle S, Ringen PA, Melle I, Larsen TK, Gjestad R, Johnsen E, et al. Cannabis use is associated with 3years earlier onset of schizophrenia spectrum disorder in a naturalistic, multi-site sample $(\mathrm{N}=1119)$. Schizophr Res (2016) 170(1):217-21. doi:10.1016/j.schres.2015.11.027

33. Stefanis NC, Dragovic M, Power BD, Jablensky A, Castle D, Morgan VA. The effect of drug use on the age at onset of psychotic disorders in an Australian cohort. Schizophr Res (2014) 156(2-3):211-6. doi:10.1016/j. schres.2014.04.003

34. Dekker N, Meijer J, Koeter M, van den Brink W, van Beveren N, Kahn RS, et al. Age at onset of non-affective psychosis in relation to cannabis use, other drug use and gender. Psychol Med (2012) 42(9):1903-11. doi:10.1017/ S0033291712000062

35. Tosato S, Lasalvia A, Bonetto C, Mazzoncini R, Cristofalo D, De Santi K, et al. The impact of cannabis use on age of onset and clinical characteristics in first-episode psychotic patients. Data from the Psychosis Incident Cohort Outcome Study (PICOS). J Psychiatr Res (2013) 47(4):438-44. doi:10.1016/j. jpsychires.2012.11.009

36. Lagerberg TV, Sundet K, Aminoff SR, Berg AO, Ringen PA, Andreassen OA, et al. Excessive cannabis use is associated with earlier age at onset in bipolar disorder. Eur Arch Psychiatry Clin Neurosci (2011) 261(6):397-405. doi:10.1007/s00406-011-0188-4

37. De Hert M, Wampers M, Jendricko T, Franic T, Vidovic D, De Vriendt N, et al. Effects of cannabis use on age at onset in schizophrenia and bipolar disorder. Schizophr Res (2011) 126(1-3):270-6. doi:10.1016/j.schres.2010. 07.003

38. Gibbs M, Winsper C, Marwaha S, Gilbert E, Broome M, Singh SP. Cannabis use and mania symptoms: a systematic review and meta-analysis. J Affect Disord (2015) 171:39-47. doi:10.1016/j.jad.2014.09.016

39. Manrique-Garcia E, Zammit S, Dalman C, Hemmingsson T, Andreasson S, Allebeck P. Prognosis of schizophrenia in persons with and without a history of cannabis use. Psychol Med (2014) 44(12):2513-21. doi:10.1017/ S0033291714000191

40. Hides L, Dawe S, Kavanagh DJ, Young RM. Psychotic symptom and cannabis relapse in recent-onset psychosis. Prospective study. Br J Psychiatry (2006) 189:137-43. doi:10.1192/bjp.bp.105.014308

41. Seddon JL, Birchwood M, Copello A, Everard L, Jones PB, Fowler D, et al. Cannabis use is associated with increased psychotic symptoms and poorer psychosocial functioning in first-episode psychosis: a report from the UK national EDEN study. Schizophr Bull (2016) 42(3):619-25. doi:10.1093/ schbul/sbv154

42. van der Meer FJ, Velthorst E, Genetic R. Outcome of psychosis I. Course of cannabis use and clinical outcome in patients with non-affective psychosis: a 3-year follow-up study. Psychol Med (2015) 45(9):1977-88. doi:10.1017/ S0033291714003092

43. Clausen L, Hjorthoj CR, Thorup A, Jeppesen P, Petersen L, Bertelsen M, et al. Change in cannabis use, clinical symptoms and social functioning among patients with first-episode psychosis: a 5-year follow-up study of patients in the OPUS trial. Psychol Med (2014) 44(1):117-26. doi:10.1017/ S0033291713000433

44. Stone JM, Fisher HL, Major B, Chisholm B, Woolley J, Lawrence J, et al. Cannabis use and first-episode psychosis: relationship with manic and psychotic symptoms, and with age at presentation. Psychol Med (2014) 44(3):499-506. doi:10.1017/S0033291713000883

45. Myles H, Myles N, Large M. Cannabis use in first episode psychosis: meta-analysis of prevalence, and the time course of initiation and continued use. Aust N Z J Psychiatry (2016) 50(3):208-19. doi:10.1177/ 0004867415599846

46. Patel R, Wilson R, Jackson R, Ball M, Shetty H, Broadbent M, et al. Association of cannabis use with hospital admission and antipsychotic treatment failure in first episode psychosis: an observational study. BMJ open (2016) 6(3):e009888. doi:10.1136/bmjopen-2015-009888

47. Gonzalez-Ortega I, Alberich S, Echeburua E, Aizpuru F, Millan E, Vieta E, et al. Subclinical depressive symptoms and continued cannabis use: predictors of negative outcomes in first episode psychosis. PLoS One (2015) 10(4):e0123707. doi:10.1371/journal.pone.0123707

48. Zorrilla I, Aguado J, Haro JM, Barbeito S, Lopez Zurbano S, Ortiz A, et al. Cannabis and bipolar disorder: does quitting cannabis use during manic/ mixed episode improve clinical/functional outcomes? Acta Psychiatr Scand (2015) 131(2):100-10. doi:10.1111/acps.12366 
49. Kim SW, Dodd S, Berk L, Kulkarni J, de Castella A, Fitzgerald PB, et al. Impact of cannabis use on long-term remission in bipolar I and schizoaffective disorder. Psychiatry Investig (2015) 12(3):349-55. doi:10.4306/ pi.2015.12.3.349

50. Kotov R, Guey LT, Bromet EJ, Schwartz JE. Smoking in schizophrenia: diagnostic specificity, symptom correlates, and illness severity. Schizophr Bull (2010) 36(1):173-81. doi:10.1093/schbul/sbn066

51. Vanable PA, Carey MP, Carey KB, Maisto SA. Smoking among psychiatric outpatients: relationship to substance use, diagnosis, and illness severity. Psychol Addict Behav (2003) 17(4):259-65. doi:10.1037/0893-164X.17.4.259

52. Berk M, Ng F, Wang WV, Tohen M, Lubman DI, Vieta E, et al. Going up in smoke: tobacco smoking is associated with worse treatment outcomes in mania. J Affect Disord (2008) 110(1-2):126-34. doi:10.1016/j.jad.2008.01.018

53. Wang HR, Woo YS, Bahk WM. Caffeine-induced psychiatric manifestations: a review. Int Clin Psychopharmacol (2015) 30(4):179-82. doi:10.1097/ YIC.0000000000000076

54. Rizkallah E, Belanger M, Stavro K, Dussault M, Pampoulova T, Chiasson JP, et al. Could the use of energy drinks induce manic or depressive relapse among abstinent substance use disorder patients with comorbid bipolar spectrum disorder? Bipolar Disord (2011) 13(5-6):578-80. doi:10.1111/j.13995618.2011.00951.x

55. Hughes K, Lowey H, Quigg Z, Bellis MA. Relationships between adverse childhood experiences and adult mental well-being: results from an English national household survey. BMC Public Health (2016) 16:222. doi:10.1186/ s12889-016-2906-3

56. Schilling EA, Aseltine RH Jr, Gore S. Adverse childhood experiences and mental health in young adults: a longitudinal survey. BMC Public Health (2007) 7:30. doi:10.1186/1471-2458-7-30

57. Bechdolf A, Thompson A, Nelson B, Cotton S, Simmons MB, Amminger GP, et al. Experience of trauma and conversion to psychosis in an ultra-highrisk (prodromal) group. Acta Psychiatr Scand (2010) 121(5):377-84. doi:10.1111/j.1600-0447.2010.01542.x

58. Varese F, Smeets F, Drukker M, Lieverse R, Lataster T, Viechtbauer W, et al. Childhood adversities increase the risk of psychosis: a meta-analysis of patient-control, prospective- and cross-sectional cohort studies. Schizophr Bull (2012) 38(4):661-71. doi:10.1093/schbul/sbs050

59. Trauelsen AM, Bendall S, Jansen JE, Nielsen HG, Pedersen MB, Trier CH, et al. Childhood adversity specificity and dose-response effect in nonaffective first-episode psychosis. Schizophr Res (2015) 165(1):52-9. doi:10.1016/j.schres.2015.03.014

60. Agnew-Blais J, Danese A. Childhood maltreatment and unfavourable clinical outcomes in bipolar disorder: a systematic review and meta-analysis. Lancet Psychiatry (2016) 3(4):342-9. doi:10.1016/S2215-0366(15)00544-1

61. Dienes KA, Hammen C, Henry RM, Cohen AN, Daley SE. The stress sensitization hypothesis: understanding the course of bipolar disorder. J Affect Disord (2006) 95(1-3):43-9. doi:10.1016/j.jad.2006.04.009

62. Myin-Germeys I, Peeters F, Havermans R, Nicolson NA, DeVries MW, Delespaul P, et al. Emotional reactivity to daily life stress in psychosis and affective disorder: an experience sampling study. Acta Psychiatr Scand (2003) 107(2):124-31. doi:10.1034/j.1600-0447.2003.02025.x

63. McLaughlin KA, Conron KJ, Koenen KC, Gilman SE. Childhood adversity, adult stressful life events, and risk of past-year psychiatric disorder: a test of the stress sensitization hypothesis in a population-based sample of adults. Psychol Med (2010) 40(10):1647-58. doi:10.1017/S0033291709992121

64. Beards S, Gayer-Anderson C, Borges S, Dewey ME, Fisher HL, Morgan C. Life events and psychosis: a review and meta-analysis. Schizophr Bull (2013) 39(4):740-7. doi:10.1093/schbul/sbt065

65. Kemner SM, van Haren NE, Bootsman F, Eijkemans MJ, Vonk R, van der Schot AC, et al. The influence of life events on first and recurrent admissions in bipolar disorder. Int J Bipolar Disord (2015) 3:6. doi:10.1186/ s40345-015-0022-4

66. Gilman SE, Ni MY, Dunn EC, Breslau J, McLaughlin KA, Smoller JW, et al. Contributions of the social environment to first-onset and recurrent mania. Mol Psychiatry (2015) 20(3):329-36. doi:10.1038/mp.2014.36

67. Etain B, Aas M, Andreassen OA, Lorentzen S, Dieset I, Gard S, et al. Childhood trauma is associated with severe clinical characteristics of bipolar disorders. J Clin Psychiatry (2013) 74(10):991-8. doi:10.4088/JCP.13m08353

68. Freeman D, Emsley R, Dunn G, Fowler D, Bebbington P, Kuipers E, et al. The stress of the street for patients with persecutory delusions: a test of the symptomatic and psychological effects of going outside into a busy urban area. Schizophr Bull (2015) 41(4):971-9. doi:10.1093/schbul/sbu173

69. Simhandl C, Radua J, Konig B, Amann BL. The prevalence and effect of life events in 222 bipolar I and II patients: a prospective, naturalistic 4 year follow-up study. J Affect Disord (2015) 170:166-71. doi:10.1016/j. jad.2014.08.043

70. Taylor PJ, Hutton P, Wood L. Are people at risk of psychosis also at risk of suicide and self-harm? A systematic review and meta-analysis. Psychol Med (2015) 45(5):911-26. doi:10.1017/S0033291714002074

71. Kooyman I, Dean K, Harvey S, Walsh E. Outcomes of public concern in schizophrenia. Br J Psychiatry Suppl (2007) 50:s29-36. doi:10.1192/bjp. 191.50.s29

72. Millier A, Schmidt U, Angermeyer MC, Chauhan D, Murthy V, Toumi M, et al. Humanistic burden in schizophrenia: a literature review. J Psychiatr Res (2014) 54:85-93. doi:10.1016/j.jpsychires.2014.03.021

73. Conley RR, Ascher-Svanum H, Zhu B, Faries DE, Kinon BJ. The burden of depressive symptoms in the long-term treatment of patients with schizophrenia. Schizophr Res (2007) 90(1-3):186-97. doi:10.1016/j.schres.2006.09.027

74. Fuller-Thomson E, Hollister B. Schizophrenia and suicide attempts: findings from a representative community-based Canadian sample. Schizophr Res Treatment (2016) 2016:3165243. doi:10.1155/2016/3165243

75. Bland RC, Newman SC, Orn H. Schizophrenia: lifetime co-morbidity in a community sample. Acta Psychiatr Scand (1987) 75(4):383-91. doi:10.1111/ j.1600-0447.1987.tb02806.x

76. Hor K, Taylor M. Suicide and schizophrenia: a systematic review of rates and risk factors. J Psychopharmacol (2010) 24(4 Suppl):81-90. doi: $10.1177 / 1359786810385490$

77. Swann AC. Thestrongrelationshipbetweenbipolarand substance-usedisorder. Ann N Y Acad Sci (2010) 1187:276-93. doi:10.1111/j.1749-6632.2009.05146.x

78. Gibson LE, Anglin DM, Klugman JT, Reeves LE, Fineberg AM, Maxwell SD, et al. Stress sensitivity mediates the relationship between traumatic life events and attenuated positive psychotic symptoms differentially by gender in a college population sample. J Psychiatr Res (2014) 53:111-8. doi:10.1016/j. jpsychires.2014.02.020

79. Collip D, Wigman JT, Myin-Germeys I, Jacobs N, Derom C, Thiery E, et al. From epidemiology to daily life: linking daily life stress reactivity to persistence of psychotic experiences in a longitudinal general population study. PLoS One (2013) 8(4):e62688. doi:10.1371/journal.pone.0062688

80. Myin-Germeys I, van Os J, Schwartz JE, Stone AA, Delespaul PA. Emotional reactivity to daily life stress in psychosis. Arch Gen Psychiatry (2001) 58(12):1137-44. doi:10.1001/archpsyc.58.12.1137

81. Myin-Germeys I, van Os J.Stress-reactivity in psychosis: evidence for an affective pathway to psychosis. Clin Psychol Rev (2007) 27(4):409-24. doi:10.1016/j.cpr.2006.09.005

82. Wieck A, Grassi-Oliveira R, do Prado CH, Rizzo LB, de Oliveira AS, Kommers-Molina J, et al. Pro-inflammatory cytokines and soluble receptors in response to acute psychosocial stress: differential reactivity in bipolar disorder. Neurosci Lett (2014) 580:17-21. doi:10.1016/j.neulet.2014.07.040

83. Luutonen S, Tikka M, Karlsson H, Salokangas RK. Childhood trauma and distress experiences associate with psychotic symptoms in patients attending primary and psychiatric outpatient care. Results of the RADEP study. Eur Psychiatry (2013) 28(3):154-60. doi:10.1016/j.eurpsy.2011.11.005

84. Collip D, Nicolson NA, Lardinois M, Lataster T, van Os J, Myin-Germeys I, et al. Daily cortisol, stress reactivity and psychotic experiences in individuals at above average genetic risk for psychosis. Psychol Med (2011) 41(11): 2305-15. doi:10.1017/S0033291711000602

85. Belvederi Murri M, Prestia D, Mondelli V, Pariante C, Patti S, Olivieri B, et al. The HPA axis in bipolar disorder: systematic review and meta-analysis. Psychoneuroendocrinology (2016) 63:327-42. doi:10.1016/j.psyneuen.2015. 10.014

86. Girshkin L, Matheson SL, Shepherd AM, Green MJ. Morning cortisol levels in schizophreniaandbipolardisorder:ameta-analysis.Psychoneuroendocrinology (2014) 49:187-206. doi:10.1016/j.psyneuen.2014.07.013

87. Holtzman CW, Shapiro DI, Trotman HD, Walker EF. Stress and the prodromal phase of psychosis. Curr Pharm Des (2012) 18(4):527-33. doi:10.2174/138161212799316280

88. Tessner KD, Mittal V, Walker EF. Longitudinal study of stressful life events and daily stressors among adolescents at high risk for psychotic disorders. Schizophr Bull (2011) 37(2):432-41. doi:10.1093/schbul/sbp087 
89. Brietzke E, Mansur RB, Soczynska J, Powell AM, McIntyre RS. A theoretical framework informing research about the role of stress in the pathophysiology of bipolar disorder. Prog Neuropsychopharmacol Biol Psychiatry (2012) 39(1):1-8. doi:10.1016/j.pnpbp.2012.05.004

90. Horesh N, Apter A, Zalsman G. Timing, quantity and quality of stressful life events in childhood and preceding the first episode of bipolar disorder. J Affect Disord (2011) 134(1-3):434-7. doi:10.1016/j.jad.2011.05.034

91. Streit F, Memic A, Hasandedic L, Rietschel L, Frank J, Lang M, et al. Perceived stress and hair cortisol: differences in bipolar disorder and schizophrenia. Psychoneuroendocrinology (2016) 69:26-34. doi:10.1016/j. psyneuen.2016.03.010

92. Corcoran C, Walker E, Huot R, Mittal V, Tessner K, Kestler L, et al. The stress cascade and schizophrenia: etiology and onset. Schizophr Bull (2003) 29(4):671-92. doi:10.1093/oxfordjournals.schbul.a007038

93. Nelson B, Fusar-Poli P, Yung AR. Can we detect psychotic-like experiences in the general population? Curr Pharm Des (2012) 18(4):376-85. doi: $10.2174 / 138161212799316136$

94. Yung AR, Nelson B, Baker K, Buckby JA, Baksheev G, Cosgrave EM. Psychotic-like experiences in a community sample of adolescents: implications for the continuum model of psychosis and prediction of schizophrenia. Aust N Z J Psychiatry (2009) 43(2):118-28. doi:10.1080/00048670802607188

95. van Os J, Linscott RJ, Myin-Germeys I, Delespaul P, Krabbendam L. A systematic review and meta-analysis of the psychosis continuum: evidence for a psychosis proneness-persistence-impairment model of psychotic disorder. Psychol Med (2009) 39(2):179-95. doi:10.1017/S0033291708003814

96. Poulton R, Caspi A, Moffitt TE, Cannon M, Murray R, Harrington H. Children's self-reported psychotic symptoms and adult schizophreniform disorder: a 15-year longitudinal study. Arch Gen Psychiatry (2000) 57(11):1053-8. doi:10.1001/archpsyc.57.11.1053

97. Newman SC, Bland RC. Life events and the 1-year prevalence of major depressive episode, generalized anxiety disorder, and panic disorder in a community sample. Compr Psychiatry (1994) 35(1):76-82. doi:10.1016/ 0010-440X(94)90173-2

98. Stroud CB, Davila J, Moyer A. The relationship between stress and depression in first onsets versus recurrences: a meta-analytic review. J Abnorm Psychol (2008) 117(1):206-13. doi:10.1037/0021-843X.117.1.206

99. Kenneson A, Funderburk JS, Maisto SA. Substance use disorders increase the odds of subsequent mood disorders. Drug Alcohol Depend (2013) 133(2):338-43. doi:10.1016/j.drugalcdep.2013.06.011

100. Alegria AA, Hasin DS, Nunes EV, Liu SM, Davies C, Grant BF, et al. Comorbidity of generalized anxiety disorder and substance use disorders: results from the National Epidemiologic Survey on Alcohol and Related Conditions. J Clin Psychiatry (2010) 71(9):1187-95. doi:10.4088/JCP.09m05328gry

101. Henquet C, Krabbendam L, de Graaf R, ten Have M, van Os J. Cannabis use and expression of mania in the general population. J Affect Disord (2006) 95(1-3):103-10. doi:10.1016/j.jad.2006.05.002

102. Semple DM, McIntosh AM, Lawrie SM. Cannabis as a risk factor for psychosis: systematic review. J Psychopharmacol (2005) 19(2):187-94. doi:10.1177/0269881105049040

103. Leite RT, Nogueira Sde O, do Nascimento JP, de Lima LS, da Nobrega TB, Virginio Mda S, et al. The use of cannabis as a predictor of early onset of bipolar disorder and suicide attempts. Neural Plast (2015) 2015:434127. doi: $10.1155 / 2015 / 434127$

104. Tucker P. Substance misuse and early psychosis. Australas Psychiatry (2009) 17(4):291-4. doi:10.1080/10398560802657314

105. Large M, Sharma S, Compton MT, Slade T, Nielssen O. Cannabis use and earlier onset of psychosis: a systematic meta-analysis. Arch Gen Psychiatry (2011) 68(6):555-61. doi:10.1001/archgenpsychiatry.2011.5

106. Cannon TD, Cadenhead K, Cornblatt B, Woods SW, Addington J, Walker E, et al. Prediction of psychosis in youth at high clinical risk: a multisite longitudinal study in North America. Arch Gen Psychiatry (2008) 65(1):28-37. doi:10.1001/archgenpsychiatry.2007.3

107. Parker G, Fletcher K. Differentiating bipolar I and II disorders and the likely contribution of DSM-5 classification to their cleavage. J Affect Disord (2014) 15(2-154):57-64. doi:10.1016/j.jad.2013.10.006

108. Tandon R, Gaebel W, Barch DM, Bustillo J, Gur RE, Heckers S, et al. Definition and description of schizophrenia in the DSM-5. Schizophr Res (2013) 150(1):3-10. doi:10.1016/j.schres.2013.05.028

109. Olfson M, Kroenke K, Wang S, Blanco C. Trends in office-based mental health care provided by psychiatrists and primary care physicians. J Clin Psychiatry (2014) 75(3):247-53. doi:10.4088/JCP.13m08834

Conflict of Interest Statement: The authors declare that the research was conducted in the absence of any commercial or financial relationships that could be construed as a potential conflict of interest.

Copyright (C) 2016 Hsieh, Godwin and Mamah. This is an open-access article distributed under the terms of the Creative Commons Attribution License (CC BY). The use, distribution or reproduction in other forums is permitted, provided the original author(s) or licensor are credited and that the original publication in this journal is cited, in accordance with accepted academic practice. No use, distribution or reproduction is permitted which does not comply with these terms. 